\title{
The effect of preoperative anxiety level on mean platelet volume and propofol consumption
}

\author{
Ali Ihssan Uysal ${ }^{1 *} \mathbb{D}$, Başak Altıparmak², Melike Korkmaz Toker ${ }^{1}$, Gülseda Dede ${ }^{1}$, Çiğdem Sezgin² and \\ Semra Gümüş Demirbilek²
}

\begin{abstract}
Background: The mean platelet volume (MPV) is an important indicator of platelet function with large platelets showing higher enzymatic and metabolic activity than other platelets. There can be a relationship between increased platelet activity and anxiety and depression. Our primary hypothesis was that patients with high anxiety scores would have higher MPV, and the secondary hypothesis was that propofol induction time and total propofol consumption within the first 30 min of surgery would be higher in patients with higher anxiety scores.

Methods: The Beck Anxiety Inventory (BAl) was administered to the participating patients 1 day before surgery to evaluate the level of anxiety. Based on the scores from the BAl, 40 patients with an anxiety score of $<8$ were assigned to the non-anxious group (Group NA) and 40 patients with an anxiety score of $\geq 8$ were assigned to the anxious group (Group A). At the anesthesia induction the mean time to achieve an entropy value below 60 (T1) was recorded. The total intraoperative propofol consumption within the first 30 min was recorded.

Results: There was a statistically significant difference between the groups in terms of preoperative MPV and demographic data, including age and sex. The mean total propofol consumption at 30 min after induction in the groups was statistically significant. The cut-off value for MPV was calculated as 9.65 .

Conclusions: The preoperative MPV values and propofol consumption at $30 \mathrm{~min}$ among patients with high preoperative anxiety scores were high. We suggest that MPV is helpful in the clinical practice in predicting the amount of anesthetic agents required for the 30 mins of anesthesia.
\end{abstract}

Keywords: Anxiety, Mean platelet volume, Propofol consumption

\section{Background}

Anxiety is an unpleasant feeling of apprehension, irritability, and strain. An individual experiencing anxiety gives a dramatic neuroendocrine response which increases cardiovascular activity and metabolism [1]. Such neuroendocrine responses result in an increase in catecholamine levels, sympathetic activity, and cortisol secretion [2].

Serotonin is an important factor in the psychopathology of anxiety disorders. Impaired serotonin (5-HT) function due to the hyperserotonergic state may lead to anxiety and fear response stimulated by amygdala [3]. Serotonin also

\footnotetext{
* Correspondence: alihsanuysal@gmail.com

${ }^{1}$ Department of Anesthesiology and Reanimation, Muğla Sıtkı Koçman

University Training and Research Hospital, Muğla, Turkey

Full list of author information is available at the end of the article
}

plays a key role in the regulation of vascular tone on the vessel wall and platelet aggregation [4]. Peripheral platelet models reflect central serotonergic function and are commonly used as an indicator of a central 5-HT metabolism. Accordingly, platelets can be considered a marker of biochemical alterations occurring in the brain in the presence of anxiety [5]. The mean platelet volume (MPV) is an important indicator of platelet function with large platelets showing higher enzymatic and metabolic activity than other platelets [6].

Previous studies have evaluated the effects of anxiety on the time required for the induction of anesthesia with propofol and propofol consumption $[7,8]$; however, there has been no study, to date, evaluating the effects of MPV on propofol induction time and propofol consumption. In the

(c) The Author(s). 2020 Open Access This article is distributed under the terms of the Creative Commons Attribution 4.0 International License (http://creativecommons.org/licenses/by/4.0/), which permits unrestricted use, distribution, and reproduction in any medium, provided you give appropriate credit to the original author(s) and the source, provide a link to the Creative Commons license, and indicate if changes were made. The Creative Commons Public Domain Dedication waiver (http://creativecommons.org/publicdomain/zero/1.0/) applies to the data made available in this article, unless otherwise stated. 
present study, we aimed to evaluate the possible relationship between preoperative anxiety, as assessed by the Beck Anxiety Inventory (BAI), 1 day prior to surgery and MPV. Our primary hypothesis was that patients with high anxiety scores would have higher MPV, and the secondary hypothesis was that propofol induction time and total propofol consumption within the first $30 \mathrm{~min}$ of surgery would be higher in patients with higher anxiety scores.

\section{Methods}

After obtaining the approval of the Clinical Trials Ethics Committee of Muğla Sttkı Koçman University and written informed consents from each patient, a screening was performed to evaluate anxiety levels in the participating patients. The study included patients from both sexes within an age range of 18 to 65 years, and at American Society of Anesthesiology (ASA) physical status I-II who were scheduled for elective laparoscopic cholecystectomy. Patients on psychotropic medication due to a psychiatric disease, patients with a neurological disorder, pregnant and breastfeeding women, patients with uncontrolled hypertension, metabolic disease or hematological disorders, patients with hypercholesterolemia and those who received medication for a chronic condition within the past 2 months, and patients with a chronic cardiac, respiratory or renal disease were excluded. The study was conducted in accordance with the principles of the Declaration of Helsinki.

The Beck Anxiety Inventory (BAI) was administered to the participating patients 1 day before surgery to evaluate the level of anxiety. According to BAI 1-7 point minimal anxiety, $8-15$ point mild anxiety, $16-25$ point moderate anxiety and 26 and above severe anxiety. We took the cutoff value of 8 was taken as the mild anxiety. Based on the scores from the BAI, 40 patients with an anxiety score of $<8$ were assigned to the non-anxious group (Group NA) and 40 patients with an anxiety score of $\geq 8$ were assigned to the anxious group (Group A). The MPV in the complete blood count test performed 1 day prior to surgery was recorded. All patients entering the operation room routinely underwent electrocardiography, non-invasive blood pressure measurement, peripheral oxygen saturation $\left(\mathrm{spO}_{2}\right)$ measurement, and entropy monitoring (GE entropy sensor, GE Healthcare, Finland).

Vascular access was attained on the dorsum of the left hand using an 18-gauge intravenous catheter and all patients premedicated with $0.02 \mathrm{mg} / \mathrm{kg}$ midazolam. A physiological saline was initiated at a rate of $15 \mathrm{mlkg}^{-1}$ $\mathrm{h}^{-1}$. Anesthesia was induced through the administration of propofol $1 \%$ at a rate of $3 \mathrm{mg} / \mathrm{kg} / 3 \mathrm{~min}$ using an infuser. The pain from the propofol infusion was rated as described elsewhere ( 0 , none; 1 , mild; 2 , moderate; 3 , severe) by an anesthesiologist who was blind to the study groups and treatments [9]. The mean time to achieve an entropy value below 60 (T1) was recorded and a remifentanil infusion was initiated for $2 \mathrm{~min}$ at a rate of $1 \mu \mathrm{g} / \mathrm{kg}^{-1} / \mathrm{min}^{-1}$. Rocuronium $0.6 \mathrm{mg} / \mathrm{kg}$ was administered for neuromuscular blockage and the Evans scores of the patients after intubation were recorded.

For the maintenance of anesthesia, intravenous propofol was continued at a rate of 3 to $7 \mathrm{mg} / \mathrm{kg}^{1} / \mathrm{h}^{-1}$ and the remifentanil infusion was continued at a rate of $0.1 \mu \mathrm{g} / \mathrm{kg}^{-1} / \mathrm{min}^{-1}$ to maintain the target entropy value of between 40 and 60 . The remifentanil infusion rate was increased to $0.3 \mu \mathrm{g} / \mathrm{kg}^{-1} / \mathrm{min}^{-1}$, if the entropy value was above 60 with a propofol infusion rate of $7 \mathrm{mg} / \mathrm{kg}^{-}$ $1 / h^{-1}$. Mechanical ventilation was continued with $3 \mathrm{~L}$ fresh gas flow containing $40 \% \mathrm{O}_{2}$ and $60 \%$ air. All patients were administered intravenous dexketoprofen 50 $\mathrm{mg}$ and tramadol $1 \mathrm{mg} / \mathrm{kg}^{-1}$ for preemptive analgesia. The total intraoperative propofol consumption within the first $30 \mathrm{~min}$ was recorded. The remifentanil infusion was ceased $10 \mathrm{~min}$ before completion of surgery, and the propofol infusion was ceased after suture placement. The time from the end of anesthesia to eye opening was recorded (T2). Along with these measurements, the mean arterial pressure (MAP), heart rate (HR), end-tidal carbon dioxide $\left(\mathrm{etCO}_{2}\right)$, and $\mathrm{spO}_{2}$ were recorded before induction, before intubation, and at 5, 10, 30, 45, and 60 min after intubation.

\section{Statistical analysis}

Previous studies in the literature were taken into consideration while estimating the sample size $[10,11]$. It was hypothesized that a $20 \%$ difference in the preoperative MPV of patients with low and high anxiety scores would be of clinical significance. The minimum number of patients in each group was calculated as 34 considering an alpha (two-tailed) of 0.05 and a power of 0.80 .

Statistical analysis was performed using the SPSS version 15.0 software (SPSS Inc., Chicago, IL, USA). The relationship between MPV and preoperative anxiety scores was evaluated using the Pearson's correlation coefficient. A receiver operating characteristic (ROC) curve analysis was performed to evaluate the relationship between the BAI scores and MPV and propofol consumption at $30 \mathrm{~min}$. A $p$ value of less than 0.05 was considered statistically significant.

\section{Results}

A total of 95 patients were evaluated using the BAI, after which, five patients who did not give their consent for participation in the study, four with a history of psychotropic drug use, and three with ASA physical status III were excluded. Finally, 83 patients were divided into two groups based on their anxiety scores (Fig. 1).

The demographic data was presented Table 1. The age, sex, and MPV were significant difference between groups. The mean MPV in the preoperative complete 


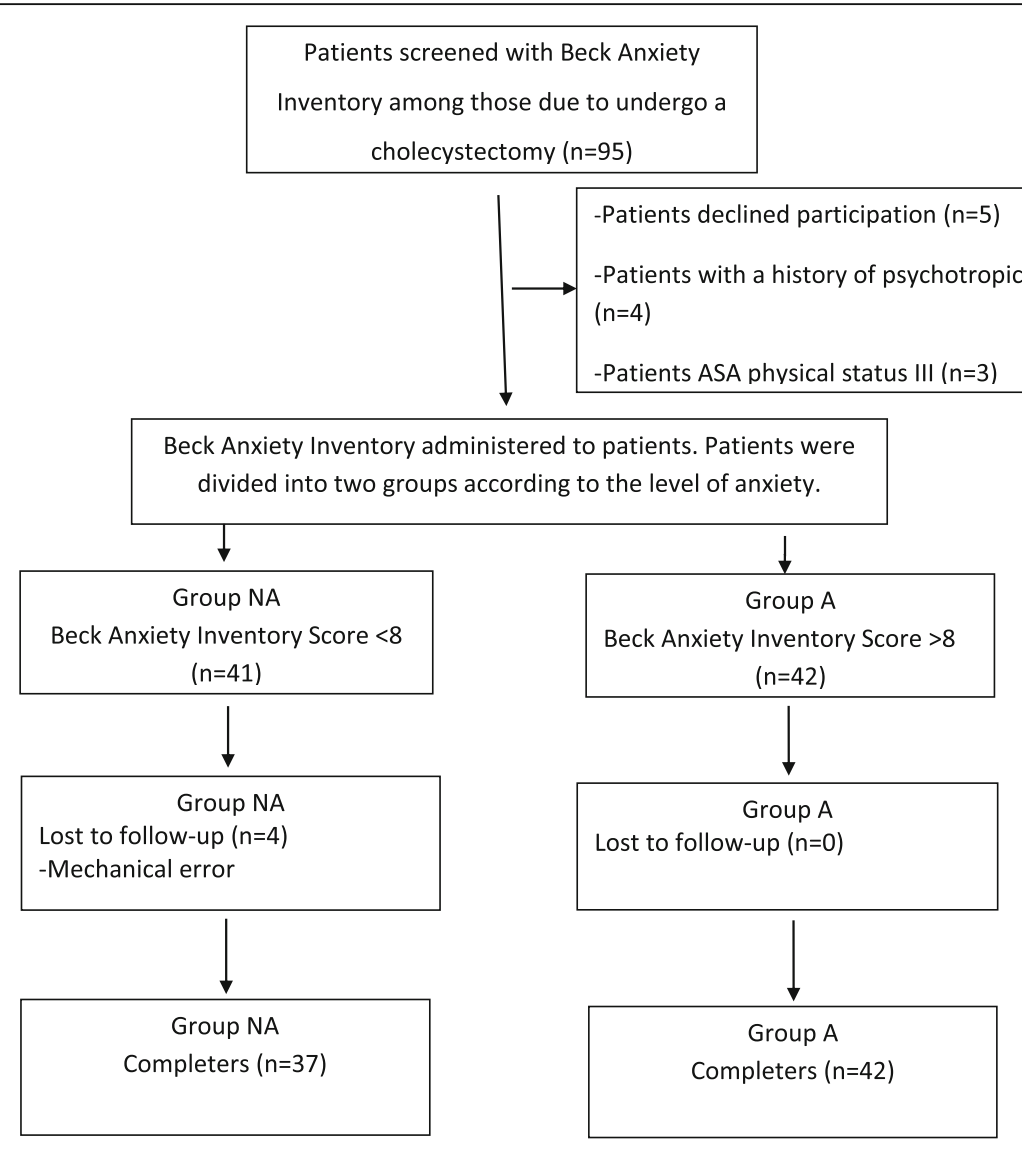

Fig. 1 Study flow chart

blood count was $10.23 \pm 1.42$ in Group A and $8.98 \pm 0.91$ in Group NA $(p=0.02)$ (Table 1).

In terms of intraoperative data, time to achieve an entropy value of below 60 after induction and the time to eye opening after surgery were similar in Group A and Group NA $(p=0.12$ and $p=0.25$, respectively). The mean total propofol consumption at $30 \mathrm{~min}$ after induction was $418.35 \pm 121.98 \mathrm{mg}$ in Group A and $344.04 \pm$ $72.03 \mathrm{mg}$ in Group NA. The difference between the groups was statistically significant $(p=0.001)$. The median value and the percentage of propofol injection pain in both groups are shown in Table 2.

Table 1 Descriptive variables of group anxious and group nonanxious

\begin{tabular}{llll}
\hline & $\begin{array}{l}\text { Group Anxious } \\
n=42\end{array}$ & $\begin{array}{l}\text { Group Non-Anxious } \\
n=37\end{array}$ & $p$ \\
\hline Age & $44.08 \pm 15.88$ & $36.09 \pm 11.28$ & 0.01 \\
Sex (F/M) & $22 / 15$ & $14 / 28$ & 0.02 \\
BMI & $23.90 \pm 4.30$ & $26.92 \pm 4.40$ & 0.28 \\
MPV & $10.23 \pm 1.42$ & $8.98 \pm 0.91$ & 0.02 \\
Platelet count & $278.85 \pm 31.34$ & $256.64 \pm 48.65$ & 0.10 \\
\hline
\end{tabular}

Results are expressed as mean \pm standard deviation or number of patients $F$ Female, $M$ Male
According to the Pearson's correlation analysis, we found a correlation between the MPV and anxiety scores in the anxious group $(r=0.336, p=0.04)$, whereas no correlation was found in the non-anxious group $(r=0.126$; $p=0.42$ ). The area under curve (AUC) for MPV was recorded as $77.3 \%$ with $5.8 \%$ standard deviation. AUC for Propofol was $69.5 \%$ with $6.2 \%$ standard deviation. The ROC curve analysis showed that the best sensitivity value was $73 \%$ and the specificity value was $76 \%$. Accordingly, the cut-off value for MPV was calculated as 9.65 (Fig. 2).

\section{Discussion}

In the present study, we found significantly higher preoperative MPV values among patients with high preoperative anxiety scores. Similarly, propofol consumption at 30 min was higher in patients with higher anxiety scores. However, we found no relationship between the time to achieve entropy value below 60 and anxiety scores.

Psychological factors have an effect on anesthetic requirements and postoperative pain in patients undergoing a selected surgical procedure. Kil et al. [10] investigated the effects of anxiety on the amount of propofol to achieve different levels of sedation. In addition, a high anxiety level increased the propofol requirement 
Table 2 Comparison of intraoperative variables of group anxious and group non-anxious

\begin{tabular}{|c|c|c|c|}
\hline & $\begin{array}{l}\text { Group Anxious } \\
n=42\end{array}$ & $\begin{array}{l}\text { Group Non-Anxious } \\
n=37\end{array}$ & $p$ \\
\hline Profofol injection pain ${ }^{a}$ & 1.00 & 1.50 & 0.06 \\
\hline \multirow[t]{4}{*}{ Profofol injection pain ${ }^{\mathrm{b}}(\mathrm{n}, \%)$} & None $(13, \% 35.1)$ & None $(7, \% 16.7)$ & \\
\hline & Mild $(13, \% 35.1)$ & Mild $(14, \% 33.3)$ & \\
\hline & Moderate $(6, \% 16.2)$ & Moderate $(13, \% 31.0)$ & \\
\hline & Severe $(5,13.5)$ & Severe $(8, \% 19.0)$ & \\
\hline Time to achieve an entropy value below 60 (sec) & $128.51 \pm 44.74$ & $133.11 \pm 34.00$ & 0.12 \\
\hline Evans score & $1.67 \pm 1.56$ & $1.66 \pm 1.76$ & 0.98 \\
\hline Propofol consumption at $30 \mathrm{~min}(\mathrm{mg})$ & $418.35 \pm 121.98$ & $344.04 \pm 72.03$ & 0.001 \\
\hline Total propofol consumption (mg) & $808.32 \pm 256.39$ & $650.45 \pm 143.34$ & 0.001 \\
\hline Total remifentanil consumption (mcg) & $423.56 \pm 91.30$ & $426.07 \pm 74.60$ & 0.89 \\
\hline Time to eye opening (sec) & $261.56 \pm 120.88$ & $224.90 \pm 156.02$ & 0.25 \\
\hline Operation time (min) & $57.70 \pm 6.30$ & $55.66 \pm 9.70$ & 0.28 \\
\hline
\end{tabular}

The other results are expressed as mean \pm standard deviation

${ }^{\text {a }}$ Propofol injection pain is expresses as median

${ }^{\mathrm{b}}$ The percentage of Propofol injection pain

for both superficial sedation (BIS 85) and moderate sedation (BIS 75). Propofol requirements for deep sedation (BIS 65) were higher with chronic anxiety, whereas no significant difference was noted in relation to state anxiety. In another study, Maranets et al. [7] reported that the baseline anxiety level increased the intraoperative analgesic requirement and, similarly, Hong et al. [8] showed a remarkable correlation between the amount of propofol required for sedation and the level of anxiety. In the present study, the time required for anesthesia induction using a constant rate of infusion of propofol was similar for patients with and without anxiety, whereas propofol consumption at 30 min was significantly higher in the anxious group.

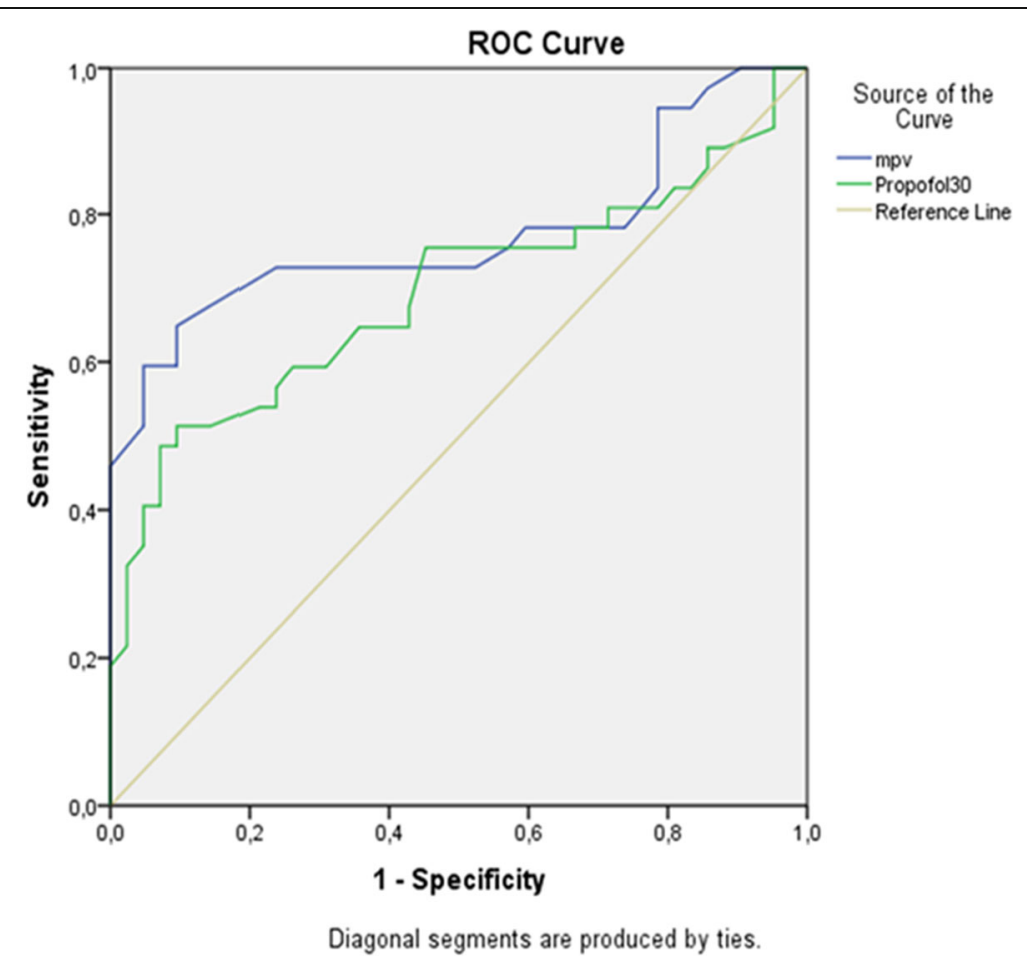

Fig. 2 ROC curve analysis and area under the curve (AUC) showing the relationship between the Beck score and MPV and propofol consumption at $30 \mathrm{~min}$ 
There are several studies in the literature evaluating the effects of age and sex on anxiety. Kil et al. [10] showed that advancing age was not related to anxiety; however, they reported a relationship with increasing pain sensitivity. Another study [12] reported higher anxiety levels in female patients, and similar to previous studies, there was a female predominance in the group of patients with higher anxiety scores. Different from the literature, however, the mean age was significantly higher in patients with a high anxiety score. There are also some studies reporting that age and gender differences can effect on platelet functions [13-15].

Previous studies also demonstrated a relationship between increased platelet activity and anxiety and depression. In a study of 15 patients, Canan and Ataoğlu [12] reported elevated MPV values in patients with major depression, and also a marked decrease in the MPV values of eight patients undergoing escitalopram therapy. Another study comparing 289 patients with major depression and healthy control subjects reported higher MPV values in the patient group [16]. Multiple changes may occur in platelet parameters in patients with anxiety disorders [17]. Increased MPV values may be indicative of increased platelet activation or the presence of enlarged and extremely flexible platelets [18]. The possible mechanisms underlying platelet abnormalities in major depression are considered to be caused by changes in the platelet functions associated with alterations in intraplatelet monoamine and catecholamine concentrations, increases in plasma 5-HT and epinephrine concentrations, and increases in intraplatelet calcium mobilization [19]. The underlying mechanism in anxiety disorders has been associated with serotonin mechanism. Vizioli et al. [20] showed that increased sympathetic activity could result in an increase in MPV values. Serotonin 5-HT2A receptors and serotonin transporter receptors in the platelets and brain are encoded by the same gene [21], and as a result, serotonin-related platelet activation was reported in patients with anxiety disorder [21]. As opposed to other studies, Gul et al. [22] found lower MPV values in patients with anxiety disorder than in the control group. Although the authors were unable to explain the actual mechanism, they suggested that abnormal 5-HT metabolism in patients with panic disorder might have led to their finding.

The MPV values were higher in patients with high anxiety scores in the present study. The calculation of the area under curve in the ROC analysis showed that preoperative MPV values performed better in detecting the presence of anxiety than the level of propofol consumption. A cut-off MPV value of 9.65 yielded the best sensitivity (73\%) and specificity (46\%) values. In our study the cut off value of BAI is accepted as mild anxiety. If another study took this cut off value moderate anxiety there may be a higher correlation between MPV and anxiety.
The anxiety has an effect on the adrenergic system [14]. An increase in the adrenergic system results in an increase in platelet volume during the production processes. In other words, patients with high levels of anxiety generally have platelets with large volumes. We think that the mechanism of adrenergic system and platelet production process can explain the correlation between MPV and anxiety.

The main limitation of the present study is that age and sex, which may affect platelet function and anxiety, were not taken into consideration when recruiting participants, and as a result, a difference was observed between the groups in terms of age and gender. Studies of more homogeneous groups involving single age and sex groups may eliminate the possible effects of age and sex on MPV values.

\section{Conclusions}

MPV is a cost-effective, fast, and easy parameter for the detection of preoperative anxiety and, based on our study results, we suggest that it is helpful in the clinical practice in predicting the amount of anesthetic agents required for the first 30 mins of anesthesia.

\begin{abstract}
Abbreviations
ASA: American Society of Anesthesiology; AUC: Area Under Curve; BAI: Beck Anxiety Inventory; BMI: Body Mass Index; etCO 2 : End-Tidal Carbon Dioxide; Group A: Anxious Group; Group NA: Non-Anxious Group; HR: Heart Rate; MAP: Mean Arterial Pressure; MPV: Mean Platelet Volume; ROC: Receiver Operating Characteristic; $\mathrm{spO}_{2}$ : Peripheral Oxygen Saturation; $\mathrm{T} 1$ : The mean time to achieve an entropy value below 60; T2: The time from the end of anesthesia to eye opening was recorded
\end{abstract}

\section{Acknowledgements}

Not applicable.

\section{Authors' contributions}

All of the authors (AIU, BA, MKT, GD, ÇS, SGD) made substantial contributions to conception and design, or acquisition of data, or analysis and interpretation of data; they have been involved in drafting the manuscript or revising it critically for important intellectual content; have given final approval of the version to be published.

\section{Funding}

No funding.

\section{Availability of data and materials}

The datasets used and/or analyzed during the current study are available from the corresponding author on reasonable request.

\section{Ethics approval and consent to participate}

This study has been approved by Muğla Sıtkı Koçman University Clinical Research Ethics Committee with decision number: XXVIII. A written informed consent form was obtained from all patients agreed to participate in the study.

Consent for publication

This manuscript does not report any individual personal data.

Competing interests

The authors declare that they have no competing interests. 


\section{Author details}

'Department of Anesthesiology and Reanimation, Muğla Sıtkı Koçman University Training and Research Hospital, Muğla, Turkey. ${ }^{2}$ Department of Anesthesiology and Reanimation, Muğla Sıtkı Koçman University, Muğla, Turkey.

Received: 31 January 2019 Accepted: 27 January 2020

Published online: 01 February 2020

\section{References}

1. Osborn TM, Sandler NA. The effects of preoperative anxiety on intravenous sedation. Anesth Prog. 2004;51(2):46-51 Available from: http://www. pubmedcentral.nih.gov/articlerender.fcgi?artid=2007471\&tool= pmcentrez\&rendertype=abstract.

2. Strike PC, Steptoe A. Psychosocial factors in the development of coronary artery disease. Prog Cardiovasc Dis. 2004;46(4):337-47 Available from: http:// www.ncbi.n/m.nih.gov/pubmed/14961456\%5Cnpapers2://publication/uuid/3 D84F51E-116F-4E5A-9B81-B9130EDAD87B.

3. Lesch K-P, Bengel D, Heils A, Sabol SZ, Greenberg BD, Petri S, et al. Association of anxiety-related traits with a polymophism in the serotonin transporter gene regulatory region. Science. 1996;274(5292):1527-31. https://doi.org/10.1126/science.274.5292.1527.

4. Vanhoutte PM. Platelet-derived serotonin, the endothelium, and cardiovascular disease. J Cardiovasc Pharmacol. 1991;71:S6-12.

5. Camacho A, Dimsdale JE. Platelets and psychiatry: lessons learned from old and new studies. Psychosom Med. 2000;62(3):326-36.

6. Martin JF, Shaw T, Heggie J, Penington DG. Measurement of the density of human platelets and its relationship to volume. Br J Haematol. 1983;54(3): 337-52

7. Maranets I, Kain ZN. Preoperative anxiety and intraoperative anesthetic requirements. Anesth Analg. 1999;89(6):1346-51 Available from: http://www. ncbi.nlm.nih.gov/pubmed/10589606.

8. Hong JY, Jee YS, Luthardt FW. Comparison of conscious sedation for oocyte retrieval between low-anxiety and high-anxiety patients. J Clin Anesth. 2005; 17(7):549-53.

9. Doenicke AW, Roizen MF, Rau J, Kellermann W, Babl J. Reducing pain during propofol injection: the role of the solvent. Anesth Analg. 1996;82:472-4.

10. Kil HK, Kim WO, Chung WY, Kim GH, Seo H, Hong JY. Preoperative anxiety and pain sensitivity are independent predictors of propofol and sevoflurane requirements in general anaesthesia. Br J Anaesth. 2012;108(1):119-25.

11. Inci A. Increased mean platelet volume in patients with Crimean Congo hemorrhagic fever. J Clin Anal Med. 2015;6(1):8-10 Available from: http:// www.jcam.com.tr/files/KATD-2271.pdf.

12. Ataoglu A, Canan F. Mean platelet volume in patients with major depression: effect of escitalopram treatment. J Clin Psychopharmacol. 2009;29(4):368-71.

13. Berlin G, Hammar M, Tapper L, Tynngård N. Effects of age, gender and menstrual cycle on platelet function assessed by impedance aggregometry. Platelets. 2019:30(4):473-9. https://doi.org/10.1080/09537104.2018.1466387.

14. Riggs BL, Khosla S, Melton LJ. Sex steroids and the construction and conservation of the adult skeleton. Endocr Rev. 2002;23:279-302.

15. Coleman JR, Moore EE, Kelher MR, Samuels JM, Cohen MJ, Sauaia A, et al. Female platelets have distinct functional activity compared with male platelets: implications in transfusion practice and treatment of traumainduced coagulopathy. J Trauma Acute Care Surg. 2019;87(5):1052-60.

16. Canan F, Dikici S, Kutlucan A, Celbek G, Coskun H, Gungor A, et al. Association of mean platelet volume with DSM-IV major depression in a large community-based population: the MELEN study. J Psychiatr Res. 2012; 46(3):298-302.

17. Aschbacher K, Mills PJ, von Känel R, Hong S, Mausbach BT, Roepke SK, et al. Effects of depressive and anxious symptoms on norepinephrine and platelet P-selectin responses to acute psychological stress among elderly caregivers. Brain Behav Immun. 2008;22(4):493-502.

18. Park $Y$, Schoene N, Harris W. Mean platelet volume as an indicator of platelet activation: methodological issues. Platelets. 2002;13(5-6):301-6 Available from: http://www.ncbi.nlm.nih.gov/entrez/query.fcgi?cmd= Retrieve\&db=PubMed\&dopt=Citation\&list_uids=12189016.

19. Nemeroff CB, Musselman DL. Are platelets the link between depression and ischemic heart disease? Am Heart J. 2000;140:57-62.

20. Vizioli L, Muscari S, Muscari A. The relationship of mean platelet volume with the risk and prognosis of cardiovascular diseases. Int J Clin Pract. 2009: 63:1509-15.
21. Parakh K, Sakhuja A, Bhat U, Ziegelstein RC. Platelet function in patients with depression. Southern Med J. 2008;101:612-7.

22. Gül IG, Eryılmaz G, Özten E, Sayar GH. Decreased mean platelet volume in panic disorder. Neuropsychiatr Dis Treat. 2014;10 Available from: http:// search.ebscohost.com/login.aspx?direct=true \&db=psyh\&AN=2014-38476$001 \&$ site=ehost-live\%5Cnhttp://gokben.hizlisayar@uskudar.edu.tr.

\section{Publisher's Note}

Springer Nature remains neutral with regard to jurisdictional claims in published maps and institutional affiliations.
Ready to submit your research? Choose BMC and benefit from:

- fast, convenient online submission

- thorough peer review by experienced researchers in your field

- rapid publication on acceptance

- support for research data, including large and complex data types

- gold Open Access which fosters wider collaboration and increased citations

- maximum visibility for your research: over $100 \mathrm{M}$ website views per year

At $\mathrm{BMC}$, research is always in progress.

Learn more biomedcentral.com/submissions 